\title{
Influência da época de colheita no teor de sólidos solúveis em frutos de minitomate
}

Influence of harvest time on the soluble solids in minitomato fruits

\author{
G. M. Maciel ${ }^{* 1}$; M. A. R. Fernandes ${ }^{1}$; V. Hillebrand ${ }^{1}$; B. N. R. Azevedo ${ }^{1}$ \\ ${ }^{1}$ Instituto de Ciências Agrárias, Universidade Federal de Uberlândia Campus Monte Carmelo, CEP 38500-000, \\ Monte Carmelo-Minas Gerais, Brasil
}

*gabrielmaciel@iciag.ufu.br

(Recebido em 02 de setembro de 2015; aceito em 30 de novembro de 2015)

Existem poucas informações publicadas sobre o efeito da época de colheita no teor de sólidos solúveis - SS ( ${ }^{\circ}$ Brix) de frutos de minitomate. Diante disso, o objetivo do trabalho foi comparar o teor de sólidos solúveis de híbridos de minitomate, portadores do hábito de crescimento determinado versus indeterminado em função da época de colheita. O experimento foi realizado em estufa agrícola, com seis tratamentos: Mascot (hábito de crescimento indeterminado), TSV918 (hábito de crescimento indeterminado), TSV912 (hábito de crescimento indeterminado), TSV678 (hábito de crescimento indeterminado), TSV1278 (hábito de crescimento determinado), TSV910 (hábito de crescimento determinado). Foram realizadas três colheitas em época distintas (90, 120 e 150 dias após o semeio - DAS) formando um fatorial $6 \mathrm{x}$ 3. Durante as duas primeiras épocas de colheita (90 e 120 DAS) obteve-se os melhores teores de SS. Houve diferença significativa para os frutos coletados no ciclo final das plantas (150 DAS). O teor de sólidos solúveis variou durante as colheitas (90, 120 e 150 DAS), sendo inferior na última colheita (150 DAS). O hábito de crescimento influenciou o teor de SS apenas no início da colheita (90 DAS).

Palavras-chave: Solanum lycopersicum L., cultivo protegido, características organolépticas

There are little reports about the effect of minitomato fruit harvest time throughout the crop cycle in relation to soluble solids-SS ( ${ }^{\circ}$ Brix) in minitomato fruits. Thus, the objective of this study was to compare the soluble solids content of hybrids minitomato with habit of indeterminate versus determinate growth as a function of the harvest season. The experiment was carried out in a greenhouse, with six treatments: Mascot (indeterminate growth habit), TSV918 (indeterminate growth habit), TSV912 (indeterminate growth habit), TSV678 (indeterminate growth habit), TSV1278 (determinate growth habit), TSV910 (determinate growth habit). Three harvests were performed at different times (90,120 and 150 DAS) in 6 x 3 factorial arrangement. During the first two harvest times (90 and 120 DAS) the highest levels SS were obtained. There were significant differences between the fruits collected at the end of the plants (150 DAS) cycle. The soluble solids content varied during harvest times (90, 120 and 150 DAS), and was lower at the last harvest (150 DAS). The growth habit influenced the SS content only at the first harvest time (90 DAS).

Keywords: Solanum lycopersicum L., protected cultivation, organoleptic characteristics

\section{INTRODUÇÃO}

O tomateiro (Solanum lycopersicum L.) é uma das hortaliças mais importantes no mundo. Segundo dados do IBGE (2015) [1], em 2014 a produção brasileira foi de 4,2 milhões de toneladas em 65 mil hectares colhidos. Dentre os tipos produzidos, tem-se o grupo dos minitomates, que integram o grupo das mini hortaliças. Este tipo de tomate possui mercado consumidor crescente na linha dos produtos diferenciados, devido ao seu tamanho reduzido e 
excelente sabor [2]. O consumo de mimitomate tem aumentado a cada ano, sendo que de 1998 a 2010 o volume comercializado passou de 129,33 para 216,86 toneladas [3].

Entre as características mais relevantes em frutos de minitomate tem se destacado o teor de sólidos solúveis nos frutos, pois proporciona sabor adocicado quando expresso em valores acima de $6{ }^{\circ}$ Brix. Programas de melhoramento genético de minitomate tem priorizado não só a obtenção de híbridos com diferentes características de frutos (cor, formato, peso e sabor), mas também com expressão do alto teor de sólidos solúveis (SS) $[4,5,6]$ acima de $6{ }^{\circ}$ Brix. O teor de sólidos solúveis corresponde aos açúcares e ácidos presentes no fruto, os quais influenciam tanto no rendimento para processamento industrial [4] quanto no sabor para consumo in natura $[7,8]$. Sabe-se que quanto maior o teor de SS, melhor é o sabor, aroma e flavor do fruto, sendo estes, importantes componentes considerados pelos consumidores [9, 10]. Ademais, o conhecimento desta característica se torna fundamental, especialmente para tomate destinado ao consumo in natura [8].

Há relatos que o teor de sólidos solúveis pode ser influenciado pelo hábito de crescimento $[11,7,12]$. Além disso, em estudos realizados por Sobreira et al. (2010) [8] com tomate do tipo cereja, foi verificado que esse teor pode ser influenciado por fatores genéticos. Schwarz et al. (2013) [10] também chegaram a essa mesma conclusão, em pesquisas com tomate em cultivo rasteiro para processamento industrial e consumo in natura.

Apesar do conhecimento sobre a influência do hábito de crescimento na expressão de sólidos solúveis, pouco se sabe a respeito do efeito da época de colheita ao longo da fase produtiva da planta em relação ao ${ }^{\circ}$ Brix em minitomate. O comércio desta olerícola exige altos teores de SS nos frutos.

Diante do exposto, o objetivo deste trabalho foi comparar o teor de sólidos solúveis de híbridos de minitomate, portadores do hábito de crescimento determinado versus indeterminado em função de diferentes períodos de colheita.

\section{MATERIAL E MÉTODOS}

O experimento foi conduzido no período de fevereiro a outubro de 2012 no município de Piracicaba-SP a $22^{\circ} 44^{\prime} 49,53$ 'S e, $47^{\circ} 31^{\prime} 35,88^{\prime \prime}$ e $615 \mathrm{~m}$ de altitude. As plantas foram cultivadas em ambiente protegido conhecido como estufa do tipo capela $(16 \times 16 \mathrm{~m})$, com pé direito de quatro metros, coberta com filme de polietileno transparente de 150 micras, aditivado contra raios ultravioleta, e laterais protegidas com telas de polipropileno preto com $30 \%$ de sombreamento.

A semeadura foi realizada no mês de fevereiro de 2012, em bandejas de poliestireno de 128 células. Passados 37 dias da semeadura, foi realizado o transplante para vasos plásticos com capacidade para cinco litros. Tanto nas bandejas quanto nos vasos foi utilizado substrato comercial a base de fibra de coco. Foram avaliados os híbridos TSV1278 e TSV910, ambos com hábito de crescimento determinado, e os híbridos TSV678, TSV918, Mascot e TSV912, com hábito de crescimento indeterminado, totalizando seis híbridos. Os híbridos avaliados apresentam formato de fruto ovalado e pequenos (10-20 g). Cada parcela foi composta por 22 plantas $\left(8,53 \mathrm{~m}^{2}\right)$, sendo vinte úteis $\left(7,75 \mathrm{~m}^{2}\right)$, distribuídas em fileiras duplas no espaçamento de $0,5 \times 0,7 \mathrm{~m}$. Entre as linhas duplas (carreadores) foi utilizado espaçamento de $0,8 \mathrm{~m}$, totalizando 660 plantas na estufa, equivalente a 2,578 plantas $\mathrm{m}^{-2}$ [660 plantas/(área da estufa $256 \mathrm{~m}^{2}$ )].

Após o transplante, todos os tratos culturais foram realizados conforme preconizado para a cultura do tomateiro cultivado em ambiente protegido [13]. Com relação ao controle de pragas, foi realizado o monitoramento a partir de armadilhas adesivas ecológicas. Essas foram distribuídas uniformemente em toda a estufa de maneira representativa (1 armadilha a cada 50 $\mathrm{m}^{2}$ ). Somente foi aplicado defensivo químico quando necessário, de acordo com o número de insetos fixados nas fitas adesivas.

Diariamente foram monitoradas as temperaturas máxima $\left({ }^{\circ} \mathrm{C}\right)$ e mínima $\left({ }^{\circ} \mathrm{C}\right)$ ocorridas no interior da estufa, com auxílio de um termômetro digital. A condutividade elétrica $\left(\mathrm{mS} \mathrm{cm}^{-1}\right)$, potencial hidrogeniônico $(\mathrm{pH})$ e temperatura da solução nutritiva $\left({ }^{\circ} \mathrm{C}\right)$ foram monitoradas utilizando condutivímetro portátil TEC-RL0C. A condutividade elétrica foi ajustada em função 
do valor da leitura. Em média, o valor da condutividade elétrica durante o experimento foi de $1,52 \mu \mathrm{S} \mathrm{cm}^{-1}$ e o $\mathrm{pH}$ 6,68. Após o transplante, entre a primeira e a oitava semana (período de formação da planta), foram utilizados macronutrientes comerciais na proporção de 1,0:1,2:1,0 de NPK. A partir da nona semana, o protocolo da fertirrigação foi alterado para solução nutritiva de produção utilizando a proporção de 1,0:0,7:2,0 de NPK. O sistema de fertirrigação foi de gotejadores tipo microtubo SPAGHETTI PEBD, sendo a frequência controlada pelo equipamento MRI/Hidrosense.

A quantificação de sólidos solúveis foi realizada utilizando frutos maduros colhidos ao longo do tempo, sendo expresso em ${ }^{\circ}$ Brix. A colheita dos frutos foi realizada em três épocas distintas quanto ao estádio fenológico das plantas [(90, 120 e 150 dias após o semeio (DAS)]. Após a colheita, os frutos foram analisados quanto ao teor de sólidos solúveis ( ${ }^{\circ}$ Brix). Para tanto, 100 frutos maduros foram colhidos nas plantas centrais de cada parcela útil e triturados em liquidificador. Posteriormente, foi realizado a leitura do valor de ${ }^{\circ}$ Brix utilizando Refratômetro Digital Portátil (Atago PAL-1 3810).

O delineamento experimental foi em blocos casualizados (DBC), em esquema fatorial 6 (híbridos) x 3 (épocas de colheita) e cinco repetições. Os dados de SS foram submetidos à análise de variância, sendo as somas dos quadrados médios comparadas pelo teste $F(\alpha=0,05)$. Para comparação das médias, foi utilizado o teste de Tukey $(\alpha=0,05)$. Os valores obtidos para teor de SS foram transformados por $\sqrt{ }(x+1 / 2)$. Foram realizados ainda contrastes ortogonais comparando o teor de sólidos solúveis dos híbridos determinados versus híbridos indeterminados empregando o teste Scheffé $(\alpha=0,05$ e 0,01$)$. Os dados foram avaliados por meio do programa estatístico SISVAR [14].

\section{RESULTADOS E DISCUSSÃO}

A média da temperatura máxima $\left({ }^{\circ} \mathrm{C}\right)$, temperatura mínima $\left({ }^{\circ} \mathrm{C}\right)$ observada no interior da estufa e a temperatura da solução nutritiva $\left({ }^{\circ} \mathrm{C}\right), \mathrm{pH}$ e condutividade elétrica $\left(\mathrm{mS} \mathrm{cm}^{-1}\right)$, durante todo o experimento foi de 36,2; 12,5;21,06; 6,6; 1,5, respectivamente (Figura 1).

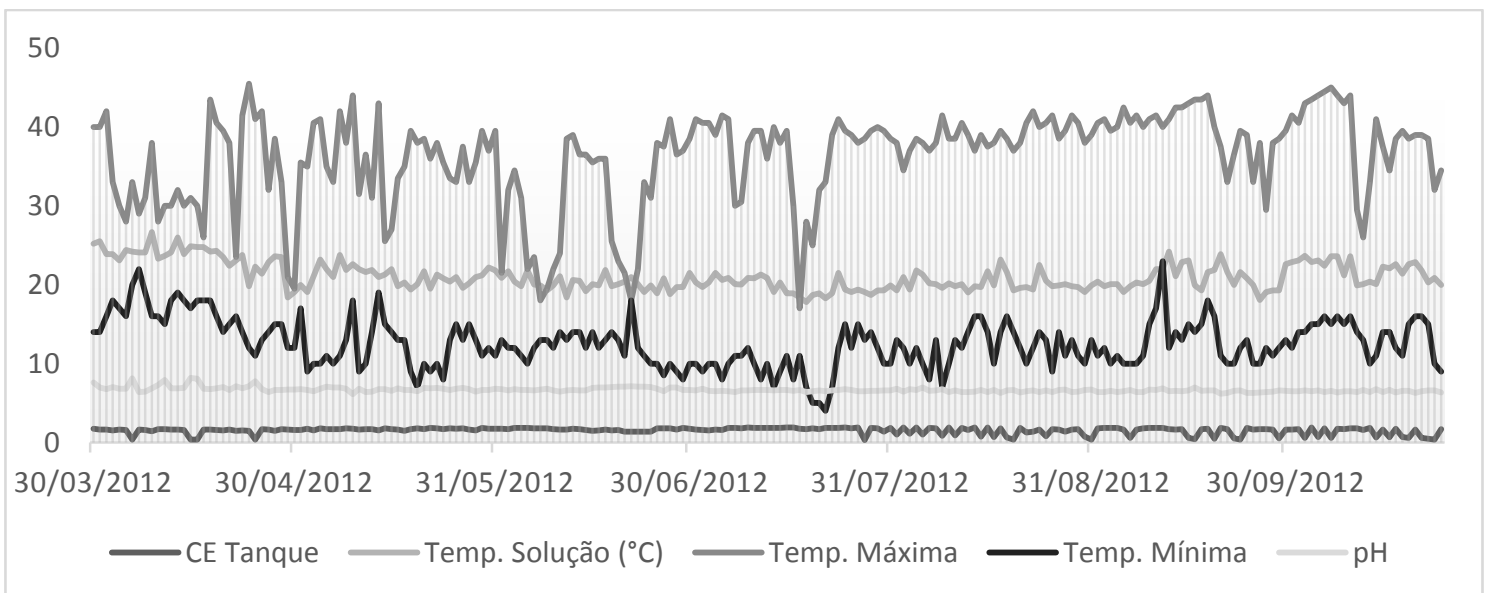

Figura 1: Condições internas da casa de vegetação (Temperatura máxima e mínima), condutividade elétrica da solução no tanque $\left(\mathrm{mS} \mathrm{cm}{ }^{-1}\right)$, temperatura da solução $\left({ }^{\circ} \mathrm{C}\right)$ e $\mathrm{pH}$ da solução monitorados diariamente.

Houve efeitos significativos da interação entre os híbridos e as épocas de colheita (Tukey, $\alpha=0,05)$. Esses resultados indicam a influência do fator genético para o teor de sólidos solúveis, o que também foi observado em experimentos realizados por Schwarz et al. (2013) [10] e Peil et al. (2014) [15]. Young et al. (1993) [16] explicam que variações no teor de sólidos solúveis entre diferentes genótipos são devidas a vários fatores que interferem na capacidade de importação de fotoassimilados pelos frutos. 
Todos os híbridos de minitomate apresentaram SS acima do desejado ( $\geq 7^{\circ}$ Brix) no ciclo inicial da cultura. No entanto, vale ressaltar a superioridade nos teores de sólidos solúveis obtidos nos híbridos TSV918 (indeterminado) e TSV910 (determinado) (9,24 e 9,10 ${ }^{\circ}$ Brix, respectivamente). O híbrido TSV912 (indeterminado), apesar de apresentar SS inicial inferior em relação aos híbridos TSV910 e TSV918, também apresentou-se superior ao desejado comercialmente $\left(8,46^{\circ}\right.$ Brix) (Tabela 1$)$.

Tabela 1: Teores de sólidos solúveis $\left({ }^{\circ}\right.$ Brix) em frutos de minitomate em diferentes épocas de colheita.

\begin{tabular}{|c|c|c|c|c|c|}
\hline & \multirow[b]{2}{*}{ Híbridos } & \multirow[b]{2}{*}{ Hábito de crescimento } & \multicolumn{3}{|c|}{ Época de colheita dos frutos } \\
\hline & & & T7=90 DAS & T8=120 DAS & T9=150 DAS \\
\hline $\mathrm{T} 1=$ & TSV1278 & Determinado & $8,37 \mathrm{cA}$ & $8,07 \mathrm{bA}$ & $6,99 \mathrm{bB}$ \\
\hline $\mathrm{T} 2=$ & TSV910 & Determinado & $9,10 \mathrm{abA}$ & $8,38 \mathrm{bA}$ & $6,97 \mathrm{bB}$ \\
\hline $\mathrm{T} 3=$ & TSV678 & Indeterminado & $7,00 \mathrm{dA}$ & $6,73 \mathrm{cA}$ & $5,44 \mathrm{cB}$ \\
\hline $\mathrm{T} 4=$ & TSV912 & Indeterminado & $8,46 \mathrm{bcA}$ & $8,51 \mathrm{bAB}$ & $7,42 \mathrm{abB}$ \\
\hline $\mathrm{T} 5=$ & TSV918 & Indeterminado & $9,24 \mathrm{aA}$ & $9,32 \mathrm{aA}$ & $8,05 \mathrm{aA}$ \\
\hline \multirow[t]{2}{*}{$\mathrm{T} 6=$} & Mascot & Indeterminado & $8,37 \mathrm{cA}$ & $7,94 \mathrm{cAB}$ & $7,17 \mathrm{bB}$ \\
\hline & $\mathrm{CV}(\%)$ & & 2,76 & 3,09 & 4,08 \\
\hline \multicolumn{3}{|c|}{ Contrastes de Interesse } & \multicolumn{3}{|c|}{$\begin{array}{c}\text { Estimativas de contrastes de interesse } \\
\text { (A) Hábito de Crescimento }\end{array}$} \\
\hline \multicolumn{3}{|c|}{$\overline{\mathrm{C} 1}=[(\mathrm{T} 1+\mathrm{T} 2) / 2-(\mathrm{T} 3+\mathrm{T} 4+\mathrm{T} 5+\mathrm{T} 6) / 4]$} & $0,46 *$ & $0,10^{\mathrm{ns}}$ & $-0,04^{\mathrm{ns}}$ \\
\hline \multicolumn{3}{|c|}{$\mathrm{C} 2=[(\mathrm{T} 1+\mathrm{T} 2) / 2-(\mathrm{T} 6)]$} & $0,36^{\mathrm{ns}}$ & $0,28^{\mathrm{ns}}$ & $-0,18^{\mathrm{ns}}$ \\
\hline \multirow{3}{*}{$\begin{array}{l}\mathrm{C} 3= \\
\mathrm{C} 4=\end{array}$} & {$[(\mathrm{T} 1)-(\mathrm{T} 3+$} & $4+\mathrm{T} 5+\mathrm{T} 6) / 4]$ & $0,10^{\mathrm{ns}}$ & $-0,06^{\mathrm{ns}}$ & $-0,03^{\mathrm{ns}}$ \\
\hline & {$[(\mathrm{T} 2)-(\mathrm{T} 3+$} & $4+\mathrm{T} 5+\mathrm{T} 6) / 4]$ & $0,83 * *$ & $0,25^{\mathrm{ns}}$ & $-0,05^{\mathrm{ns}}$ \\
\hline & & & \multicolumn{3}{|c|}{ (B) Época de Colheita } \\
\hline \multicolumn{3}{|c|}{$\mathrm{C} 5=[(\mathrm{T} 7)-(\mathrm{T} 8+\mathrm{T} 9) / 2]$} & \multicolumn{3}{|c|}{$5,04 * *$} \\
\hline \multirow{2}{*}{$\begin{array}{l}\mathrm{C} 6= \\
\mathrm{C} 7=\end{array}$} & \multicolumn{2}{|c|}{ [(T8)-(T7+T9)/2] } & \multicolumn{3}{|c|}{$2,66^{*}$} \\
\hline & \multicolumn{2}{|c|}{ [(T9)-(T7+T8)/2] } & \multicolumn{3}{|c|}{$-7,70 * *$} \\
\hline
\end{tabular}

[( $x)$ Médias seguidas da mesma letra não diferem entre si pelo teste de Tukey $(p=0,05)]$ minúsculas na coluna e maiúsculas na linha.

$(y) * *, *, n s=$ significativo $p=0,01, p=0,05$ e não significativo, respectivamente, pelo teste

$$
\text { Scheffé. }
$$

Aos 120 dias após a semeadura (DAS) o híbrido TSV918 apresentou maior ${ }^{\circ}$ Brix $(9,32)$ que os demais híbridos. Ambos híbridos com hábito de crescimento determinado (TSV1278 e TSV910) foram similares quanto ao teor de sólidos solúveis, sendo 8,07 e 8,38 ${ }^{\circ}$ Brix respectivamente (Tabela 1).

Decorridos 150 dias após semeio, no final do ciclo, o híbrido TSV918 apresentou 8,05 ${ }^{\circ}$ Brix, se diferenciando significativamente dos híbridos (TSV678, TSV910, Mascot e TSV1278). Os teores de sólidos solúveis obtidos no presente experimento variaram de 5,44 a 9,32 ${ }^{\circ}$ Brix , sendo valores acima dos obtidos por Sobreira et al. (2010) [8], em tomate tipo cereja (1,18 a $6,61{ }^{\circ}$ Brix). No presente experimento o ${ }^{\circ}$ Brix médio foi 2,37 vezes maior que a média obtida por Sobreira et al. (2010) [8] (7,86 e 3,31 ${ }^{\circ}$ Brix, respectivamente) (Tabela 1). Estes resultados demonstram o alto potencial dos híbridos avaliados no presente experimento para teor de sólidos solúveis.

Quanto ao contraste entre o potencial dos híbridos determinados versus indeterminados (C1) pode-se observar efeitos significativos (Scheffé, 5\% de probabilidade). Os híbridos determinados se diferenciaram significativamente em relação aos híbridos indeterminados, conforme pode ser observado no $\mathrm{C} 1\left(0,46{ }^{\circ}\right.$ Brix $)$ na primeira época de colheita (90 DAS). Contudo, não houve efeito significativo nas demais épocas de colheita (120 e 150 DAS). Vale ressaltar a significância (Scheffé, 1\% de probabilidade) apresentada no C4 (TSV910, híbrido determinado versus grupo dos híbridos indeterminados), revelando alto potencial no início da colheita (0,83 ${ }^{\circ}$ Brix) (Tabela 1). Contudo, Schwarz et al. (2013) [10] obtiveram em diferentes híbridos de tomate, cultivados de forma rasteira, maiores teores de sólidos solúveis em híbrido 
de crescimento indeterminado. Fridman et al. (2002) [11] explicam que o hábito de crescimento indeterminado influencia positivamente o teor de sólidos solúveis em frutos de tomate, pelo fato dessas plantas possuírem maior proporção de número de folhas por fruto em relação às plantas de crescimento determinado. Neste sentido, o acúmulo de açúcares nos frutos está relacionado com a assimilação de $\mathrm{CO}_{2}$ pelas folhas [17], onde plantas com hábito de crescimento indeterminado podem apresentar maior teor de SS devido ao maior número de folhas.

Atualmente, os programas de melhoramento genético de olerícolas priorizam a obtenção de cultivares portadoras de hábito de crescimento determinado, por apresentar concentração do período de florescimento e de produção $[12,10]$. Outra vantagem do hábito de crescimento determinado em olerícolas é a redução dos tratos culturais, como a desfolha e poda apical, reduzindo o custo de produção e também a transmissão de patógenos através das ferramentas utilizadas nessas operações [12].

Referente ao efeito das épocas de colheita de forma generalizada, independentemente do hábito de crescimento, os híbridos mantiveram os melhores teores de SS nas duas primeiras épocas de colheita (90 e 120 DAS). Houve diferença significativa quando coletado no ciclo final das plantas (150 DAS), o que requer atenção durante a condução da cultura visando amenizar tais efeitos para não afetar a comercialização. Faz-se necessário novas pesquisas especialmente relacionadas ao final do ciclo do tomateiro, da qual as últimas colheitas, são afetadas de forma pronunciada.

\section{CONCLUSÃO}

O teor de sólidos solúveis variou durante as colheitas (90, 120 e 150 DAS), sendo inferior na última colheita (150 DAS).

O hábito de crescimento influenciou o teor de SS apenas no início da colheita (90 DAS).

\section{REFERÊNCIAS BIBLIOGRÁFICAS}

1. IBGE - Instituto Brasileiro de Geografia e Estatística. Levantamento sistemático da produção agrícola. Disponível

ftp://ftp.ibge.gov.br/Producao_Agricola/Levantamento_Sistematico_da_Producao_Agricola_[mensal]/ Fasciculo/lspa_201502.pdf

2. Filgueira FAR. Novo manual de Olericultura: Agrotecnologia moderna na produção e comercialização de hortaliças. Viçosa: UFV, 2008. 421p.

3. CEASA-RS - Centrais de Abastecimento do Rio Grande do Sul SA. Cotações. 2011. Disponível em: http://www.ceasa.rs.gov.br/

4. Giordano LB, Silva JBC, Barbosa V. Escolha de cultivares e plantio. In: Silva, J. B. C.; Giordano LB, editores. Tomate para processamento industrial. Brasília: Embrapa, 2000. p. 36-59.

5. Ferreira SMR, Freitas RJS, Lazzari EN. Padrão de identidade e qualidade do tomate (Lycopersicon esculentum) de mesa. Ciência Rural, 2004 fev;34(1):329-335, doi: http://dx.doi.org/10.1590/S010384782004000100054

6. Melo PCT, Vilela NJ. Desafios e perspectivas para a cadeia brasileira do tomate para processamento industrial. Horticultura Brasileira, 2005 jan/mar;23(1):154-157, doi: http://dx.doi.org/10.1590/S010205362005000100032.

7. Ferreira MMM, Ferreira GB, Fontes PC, Dantas JD. Qualidade do tomate em função de doses de nitrogênio e da adubação orgânica em duas estações. Horticultura Brasileira, 2006 abr/jun;24(2):141145, doi: http://dx.doi.org/10.1590/S0102-05362006000200003.

8. Sobreira FM, Sobreira FM, Almeida GD, Coelho RI, Rodrigues R, Matta FP. Qualidade de sabor de tomates dos tipos salada e cereja e sua relação com caracteres morfoagronômicos dos frutos. Ciência e Agrotecnologia, 2010 jul/ago;34(4):1015-1023, doi: http://dx.doi.org/10.1590/S141370542010000400031 .

9. Auerswald H, Schwarz D, Kornelson C, Krumbein A, Brückner B. Sensory analysis, sugar and acid content of tomato at different EC values of the nutrient solution. Scientia Horticulturae, 1999 dec;82(4):227-242, doi: 10.1016/S0304-4238(99)00058-8. 
10. Schwarz K, Resende JTV, Preczenhak AP, Paula JT, Faria MV, Dias DM. Desempenho agronômico e qualidade físico-química de híbridos de tomateiro em cultivo rasteiro. Horticultura Brasileira, 2013 jul/set;31(3):410-418, doi: http://dx.doi.org/10.1590/S0102-05362013000300011.

11. Fridman E, Liu YS, Carmel-Goren L, Gur A, Shoresh M, Pleban T, Eshed Y, Zamir D. Two tightly linked QTLs modify tomato sugar content via different physiological pathways. Molecular Genetics and Genomics, 2002 jan; 266(5):821-826, doi: 10.1007/s00438-001-0599-4.

12. Piotto FA, Peres LEP. Base genética do hábito de crescimento e florescimento em tomateiro e sua importância na agricultura. Ciência Rural, 2012 nov;42(11):1941-1946, doi: http://dx.doi.org/10.1590/S0103-84782012001100006

13. Alvarenga, MAR. Tomate: produção em campo, em casa-de-vegetação e em hidroponia. Lavras: UFLA, 2013. 455p.

14. Ferreira DF. Sisvar: a computer statistical analysis system. Ciência e Agrotecnologia, 2011 nov/dec;35(6):1039-1042, doi: http://dx.doi.org/10.1590/S1413-70542011000600001.

15. Peil RMN, Albuquerque Neto AAR, Rombaldi CV. Densidade de plantio e genótipos de tomateiro cereja em sistema fechado de cultivo em substrato. Horticultura Brasileira, 2014 abr/jun; 32(2): 234240, doi: http://www.scielo.br/pdf/hb/v32n2/0102-0536-hb-32-02-00234.pdf.

16. Young TE, Juvik JA, Sullivan JG. Accumulation of the components of total solids in ripening fruits of tomato. Journal of the American Society for Horticultural Science, 1993; 118(2): 286- 292, doi: http://journal.ashspublications.org/content/118/2/286.full.pdf+html.

17. Yelle S, Chetelat RT, Dorais M, DeVena JW, Bennett AB. Sink metabolism in tomato fruit: Genetic and biochemical analysis of sucrose accumulation. Plant Physiology. 1991 Apr;95(4):1026-1035, doi: http://dx.doi.org/10.1104/pp.95.4.1026 